See Article page 1050.

\section{Commentary: In the era of mitral valve-in-valve therapy, mechanical prosthesis in young patients does not deserve to be forgotten}

\author{
Francesco Formica, MD, Francesco Maestri, MD, and \\ Francesco Nicolini, MD, PhD
}

Chen and colleagues ${ }^{1}$ from Memorial Hospital of Taoyaun in Taiwan analyzed, retrospectively, the results of patients who received either biological or mechanical valve for mitral valve replacement in rheumatic heart disease. Patient data were extracted from the National Health Insurance administrative database in Taiwan. Propensity score analysis yielded 2 paired groups of 788 patients. No significant difference in terms of in-hospital mortality were observed between the 2 matched groups. Regarding late outcomes, all-cause mortality at 10 years was in favor of the mechanical valve group, risk of stroke tended to be higher in the mechanical group without statistical significance, and finally biological valve group reported a higher incidence of reoperation. No differences were reported between the groups in terms of bleeding and thromboembolic events during follow-up. Moreover, the authors have reported a beneficial long-term of mechanical valve in patients younger than age 65 years. The authors concluded recommending a mechanical valve in patients younger than 65 years with rheumatic heart disease.

Results and conclusions of this study open up a discussion about a recently debated topic: How much do we have to favor the choice of a mechanical prosthesis in young patients (eg, age $<65$ years) in an era where the results from transcatheter mitral valve-in-valve (ViV) procedures are increasingly encouraging? In a recent study by Javadikasgari and

\footnotetext{
From the Cardiac Surgery Unit, University Hospital of Parma, and Department of Medicine and Surgery, University of Parma, Parma, Italy.

Disclosures: The authors reported no conflicts of interest.

The Journal policy requires editors and reviewers to disclose conflicts of interest and to decline handling or reviewing manuscripts for which they may have a conflict of interest. The editors and reviewers of this article have no conflicts of interest.

Received for publication March 28, 2021; revisions received March 28, 2021; accepted for publication March 29, 2021; available ahead of print April 2, 2021.

Address for reprints: Francesco Formica, MD, UO Cardiochirurgia, Azienda Ospedaliera Universitaria di Parma, Via Antonio Gramsci, 14, 43126, Parma, Italy (E-mail: francescoformica.hs@gmail.com).

J Thorac Cardiovasc Surg 2023;165:1061-2

$0022-5223 / \$ 36.00$

Copyright (c) 2021 by The American Association for Thoracic Surgery

https://doi.org/10.1016/j.jtcvs.2021.03.097
}

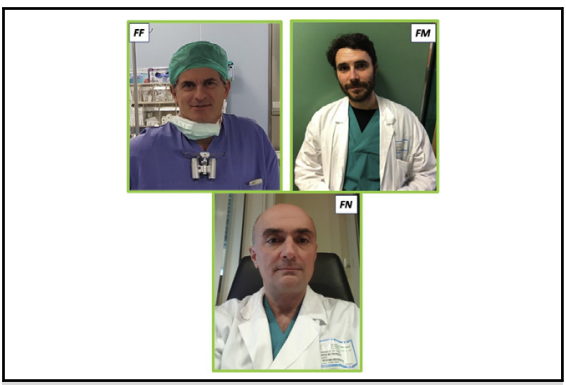

Francesco Formica, MD, Francesco Maestri, MD, and Francesco Nicolini, MD, PhD

$$
\begin{aligned}
& \text { CENTRAL MESSAGE } \\
& \text { In young patients, mechanical } \\
& \text { prosthesis for mitral valve } \\
& \text { replacement is still safe and de- } \\
& \text { serves not to be forgotten- } \\
& \text { even in this era in which mitral } \\
& \text { valve-in-valve therapy gives } \\
& \text { encouraging results. }
\end{aligned}
$$

colleagues $^{2}$ at the Cleveland clinic, the authors observed that in patients undergoing reoperation for mitral biological prosthesis degeneration, those undergoing a prosthesis replacement associated with another surgical procedure had very high surgical risk compared with those undergoing isolated replacement who had a surgical risk close to zero. When commenting on that article, we highlighted the concept that high-risk patients were evaluated by a multidisciplinary team to select those who could benefit from a mitral $\mathrm{ViV}$ approach. ${ }^{3}$ In fact, this procedure (especially the transfemoral approach) has been reported to be safe in selected high-risk surgical patients. ${ }^{4}$ Some recently published studies have reported the advantage of using the mechanical prosthesis compared with bioprosthesis in young subjects undergoing mitral valve replacement in terms of greater long-term survival and lower rate of reoperation for mechanical prosthesis. ${ }^{5,6}$ However, use of a bioprosthesis for mitral valve replacement in young subjects is becoming more frequent, due to the combination of 2 factors: a patient's refusal of lifelong anticoagulation therapy and the evidence of recent positive results of $\mathrm{ViV}$ procedures. In the study by Chen and colleagues, ${ }^{1}$ it is evident that after 6 to 8 years, patients in the biological group have a higher incidence of reoperation and a higher mortality. The long-term survival difference observed after the implantation of a mechanical versus a biological prosthesis might have been influenced by the low 
performance of a degenerated biological valve, a process that may happen very soon after surgery, mainly in young patients. This point is of paramount importance and should be strongly considered in the surgical plan. In fact, because the patients who underwent combined prosthetic valve replacement would became high-risk surgical patients compared with those patients who received an isolated prosthesis replacement, ${ }^{3}$ considering that the incidence of embolic and bleeding events are similar between the 2 types of prosthesis ${ }^{1,5,6}$ and in light of the most recent evidence regarding the promising results of mitral $\mathrm{ViV}$ procedures, ${ }^{4,7}$ surgeons must not depart from the standard indication of offering a mechanical prosthesis for young patients and should consider the biological prosthesis only for those who refuse or who do not tolerate the anticoagulant therapy and in cases of isolated mitral valve replacement that would better tolerate the surgical risk of reoperation in the future.

\section{References}

1. Chen C-Y, Chan Y-H, Wu VC-C, Liu K-S, Cheng Y-T, Chu P-H, et al. Bioprosthetic versus mechanical mitral valve replacements in patients with rheumatic heart disease. J Thorac Cardiovasc Surg. 2023;165:1050-60.e8.

2. Javadikasgari H, Chemtob RA, Gillinov AM, Pettersson GB, Lowry AM, Desai MY, et al. Outcomes of mitral valve re-replacement for bioprosthetic structural valve deterioration. J Thorac Cardiovasc Surg. August 25, 2020 [Epub ahead of print].

3. Formica F, Nicolini F. Commentary: mitral bioprosthesis degeneration: looking for a benchmark to tailor the correct procedure to the patient. J Thorac Cardiovasc Surg. October 9, 2020 [Epub ahead of print].

4. Whisenant B, Kapadia SR, Eleid MF, Kodali SK, McCabe JM, Krishnaswamy A, et al. One-year outcomes of mitral valve-in-valve using the SAPIEN 3 transcatheter heart valve. JAMA Cardiol. 2020;5:1245-52.

5. Kaneko T, Aranki S, Javed Q, McGurk S, Shekar P, Davidson M, et al. Mechanical versus bioprosthetic mitral valve replacement in patients $<65$ years old. J Thorac Cardiovasc Surg. 2014;147:117-26.

6. Schnittman SR, Itagaki S, Toyoda N, Adams DH, Egorova NN, Chikwe J. Survival and long-term outcomes after mitral valve replacement in patients aged 18 to 50 years. J Thorac Cardiovasc Surg. 2018;155:96-102.

7. Simonetto F, Purita PAM, Malerba M, Barbierato M, Pascotto A, Mangino D, et al. Surgical redo versus transseptal or transapical transcatheter mitral valve-in-valve implantation for failed mitral valve bioprosthesis. Catheter Cardiovasc Interv. 2021;97:714-22.
See Article page 1050.

\section{Commentary: Different problem, different place...same conversation}

\author{
Andrew M. Vekstein, MD, and \\ Oliver K. Jawitz, MD, MHS
}

The choice between mechanical valve or bioprosthetic valve replacement in patients with severe mitral disease remains controversial. ${ }^{1}$ The maximum age at which mechanical replacement is recommended has been cited as between 65 and 70 years. $^{2}$ The option for future valve-in-valve transcatheter replacement has driven a recent shift toward bioprosthetic valve use; however, there is more experience with this approach in the aortic position. ${ }^{3,4}$ The ideal valve choice in patients with severe rheumatic mitral disease

\footnotetext{
From the Division of Cardiovascular and Thoracic Surgery, Department of Surgery, Duke University Medical Center, Durham, NC.

Disclosures: The authors reported no conflicts of interest.

The Journal policy requires editors and reviewers to disclose conflicts of interest and to decline handling or reviewing manuscripts for which they may have a conflict of interest. The editors and reviewers of this article have no conflicts of interest.

Received for publication March 21, 2021; revisions received March 21, 2021; accepted for publication March 23, 2021; available ahead of print March 26, 2021.

Address for reprints: Oliver K. Jawitz, MD, MHS, Department of Surgery, Duke University Medical Center, Box \#3850, Durham, NC, 27710 (E-mail: oliver.jawitz@ duke.edu)

J Thorac Cardiovasc Surg 2023;165:1062-3

$0022-5223 / \$ 36.00$

Copyright (c) 2021 by The American Association for Thoracic Surgery

https://doi.org/10.1016/j.jtcvs.2021.03.071
}

Check for updates

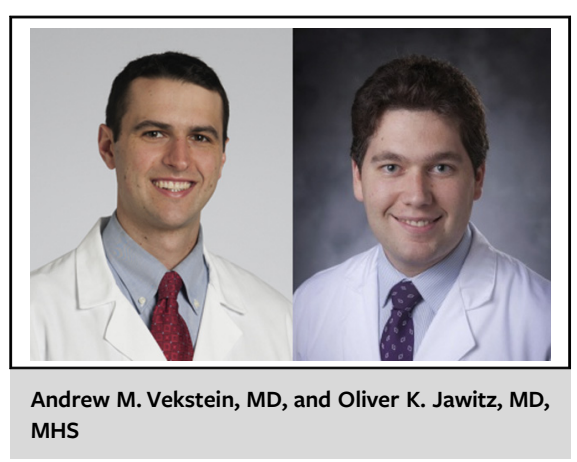

CENTRAL MESSAGE

The relationship of patient age and long-term outcomes

following bioprosthetic valve versus mechanical mitral valve replacement is similar in patients with rheumatic heart disease and those with degenerative heart disease.

remains unclear. Rheumatic etiologies (RHD) continue to represent the most common cause of mitral valve disease in the developing world. Although this disease affects 